\title{
Modern Teaching Versus Traditional Teaching- Albanian Teachers Between Challenges and
} Choices

\author{
Msc. Valbona Balliu \\ Msc. Mimoza Belshi
}

\begin{abstract}
Education lies in the foundations of the nation. Providing knowledge to generations, consolidating their future, inspiring them to incarnate benevolence and esteem splendor, valor and good principles has been one of the oldest professions of mankind, the noblest and the most difficult tasks. It is very significant that Albania and its schools have been subject of this paper. The 25-year period of the country's transition and the opening of the Albanian society to the Western World Modernization brought profound changes to the Albanian education institutions, in terms of the curricula, management and the teaching processes. The greatest part of teachers in Albania was educated during the communist period, where pedant and traditional teaching prevailed, mainly deriving from the Russian Academics. Traditional methods consider teachers as the center of the teaching process; as well as managers and the main and referential source of the scientific information. Novelties in the teaching-learning methods applied by Western Schools focus on student centered teaching; they create a variety of situations in which students evolve critical thinking. These methods have been acquired by teachers but, in the conclusions of our paper we noticed that, occasionally, they applied traditional teaching methods (especially in the scientific subjects). There is still space and worth for discussion regarding traditional teaching methods versus the modern ones. Various scholars have considered traditional teaching as the method developing theoretical thinking, whereas modern teaching develops practical skills, pragmatist and able to be oriented to the frenetic development of the world. Teachers, especially those teaching subjects like mathematics, physics and chemistry, consider traditional teaching to be more serious since students achieve better results in these subjects when outdated teaching methods have been applied. This paper and its conclusions can be considered interesting since confrontation of ideas regarding teaching methods remains a challenge for all teachers.
\end{abstract}

Keywords: modern teaching, traditional teaching, teachers, methods, school

\section{Introduction}

This writing aims to deal with traditional and modern teaching methods and is based on our twenty and odd years of experience in education. In the course of our relatively long experience and our attempts to do the best in teaching, we have often been faced with two alternatives in terms of selecting teaching methodologies; using the traditional or modern methods of teaching. Teaching is art, perhaps one of the most difficult processes since, providing cognition which remains in the students' consciousness and serves (as a useful means during the whole course of their life, is a real challenge. During these years of transition, when the Albanian education system has been leaping forward to approaching European education, we have been enjoying the progress results; however, we cannot say that every single phase of the progress was as successful as the others. Education is a progressive process, going hand in hand with human development in general as well as with its cultural, technological and social progress; education should be as much coherent and updated as possible, it should be based on effective curricula and be conveyed by people with deep scientific, pedagogical, methodological and ethical knowledge.

Means available to present-day teachers to realize effective teaching processes are endless. This freedom in choosing teaching methods, releases a great number of ideas to be used in our classrooms. The time of our students is priceless so it is very important for teachers to compare, analyze and evaluate methods they are using to motivate students and realize a qualitative teaching. In our research we were focused in teaching methods that have been widely used recently. In the theoretical study of these methods we are presenting our observations and experience as well as that of some other 
colleagues of ours, related to the work with students. However, by reading this work or any other studies over teaching methods, nobody can say which method is the most successful or the least successful; Regarding this issue (Kenneth T. Henson claims; "Methods are better for some purpose, (but there is no method simply the best for everything".

We agree with the opinion many teachers hold that, the main factor to be considered in selecting teaching methods are the students with their needs and characters since methods working properly for some students seem to be ineffective for the others; this is crucial especially when we intend to involve them all. In this writing we have been trying to present a variety of methods as well as the ways to make them as effective as possible.

\section{Teaching is both art and science}

Thirty years ago, the psychologist Silberman stated the following; "To be sure - teaching like the practice of medicine - is very much an art as far as it requires the use of one's talent and creativity; just like medicine, it is, or, should be science. This is why it involves a repertoire of techniques, procedures and wants to be described, conveyed and improved. Teachers, just like doctors, become great only when they manage to add their creativity and inspiration to this basic repertoire".

In his work, Flinders states;

"The art teaching entails various compound aspects of traditional teaching". It is; (

Communication

Perception

Collaboration

Objectivity in evaluation

Procedures similar to those used by scientists in their scientific work have been used in teaching, too. In many classes, the teachers' performance has been analyzed in four steps as in the following; (

Problem identification,

Setting objectives

Formulating a series of logical steps useful to reach the aims.

Data collection.

Therefore, teachers decide what kind of students' conduct to measure and later on they use the most suitable method to measure it.

\section{The importance of method selection}

It is not sufficient that teachers know only the end result to be achieved; they should also know the ways to reach their aims, that is, what teaching methods to use. Therefore, which is the best method? In the last decades of the past century, the Albanian school and the teaching processes have been noticed for the use of the traditional methods used. This kind of teaching features into conveying facts, rules and application of exercises to help knowledge acquisition. However, nowadays teaching processes require conveying concepts, models and abstractions, using strategies that aim to emphasize problem solution. Both types of methods should be combined in the teaching process by using various strategies to make students capable of resolving problems as well as of thinking critically and working together.

The reason is simple; the technologically developed societies require people who are able not only to memorize facts, which is done quite well by computers, but who can understand the information they need easily, are able to apply it effectively and make use of it all their lives. That is why it is necessary for teachers, firstly, to be capable of knowing and comparing models and to build their teaching and learning processes themselves, basing on basic knowledge and wants related to them.

\section{Traditional teaching methods}

Three are the main widely-used in the Albanian traditional education, as in the following; ( 


\section{Lectures and direct guiding;}

In traditional teaching - a method that has been used by many teachers during their long experience in education, the basic scientific information was conveyed by means of direct lecturing and guidelines provided by teachers. This method, having the teacher as the centre of teaching during classes, emphasizes teaching processes are led by teachers. Students expect to listen to lectures and learn by them.

Tests and exams are the best tools to measure students' performance and the main indicator for knowledge acquisition. Students belong to and sit in the same class and they are provided two kinds of separated tests, A and B. Most of the tests have been taken from the fundamental sources suchlike school textbooks relevant to the taught topics.

\section{Listening and observation}

Teachers discuss with their students about the subject, expecting them to learn everything through lecturing during classes.

For thousands of years traditional teaching has been in the centre of activities in schools and has given shape to the minds of (erudite people and artists as well as to the ordinary men and women... In a younger age, people were supposed to sit in formal education involving the teacher and a group of students gathered in a certain classroom. By using the traditional methods of teaching in formal education, students learn what they need to be successful in their lives. Traditional teaching methods have long been judged as positive and has been tested to be successful; however it has some disadvantages, too, especially regarding the present-day scale of development, when technology has greatly improved teaching effectiveness, making teaching -learning processes more attractive and enjoyable by enhancing interactive relations among students as well as by means of the scientific and educative information schools provide.

\section{Modern teaching methods}

Nowadays, the outstanding achievements in all fields of sciences, in technique and technology as well as in other fields of human development, are constantly inflicting more and more profound changes in the organization of the teaching processes, in order to make it perfect as well as to ensure easier ways for students to acquire knowledge, skills and wants. Such changes are aiming to prepare younger generations to be capable of facing $21^{\text {st }}$ century challenges as well as to be skilled and competitive to the labour market. In order to make use of the contemporary teaching methods to all levels of education, changes began to take place into the organization of classes, the application of new teaching techniques and interactive methods, etc. However, great changes took place in the forms of organizing the teaching activities. Effective teaching in a certain classroom depends, firstly, on the teachers' skills to maintain and raise the interest of the students in what is being taught. Engagement of communities to bring changes in education is considerable; millions of Euros have been spent to train and qualify teachers in order to further develop their capacities as well as to integrate them in the global currents of education. The fact that, in all societies of the world, education is a challenge requiring approaching and reproaching in order to find the most adequate ways for the education of younger generations who will have the fates of the countries of the globe as a whole in the future, cannot be disputed.

Teachers are maintaining the course to progress being even supported by the curricular changes the Albanian state has foreseen. These changes require adequate application of the New Curricula as well as permanent professional development for teachers in order to contribute into increasing quality in the field of education.

Respectively, they entail changes into the roles of teachers and students by means of participation of the communities into the life of the school as well as the interaction of many other education factors.

Students' creativity is to be detected and made use of by creative teachers who should enhance such values even by getting out of books and traditional methods, by further developing the students' creative imagination and making them understand that there are too many options to resolve a problem, so students should consider them deeply and make use of all the potential choices.

\section{Use of new technologies in teaching increases its quality}

Technological development in the world is progressing with the speed of light compared to the developments in education which are progressing very slowly. The main commitment of education and its compound elements is to get rid of the ignorance and to disperse the light of knowledge. The interest and the involvement of both the society and the individuals should be in a higher level than they actually are. Education in Kosovo is not following the steps of global developments 
which are giving the world a new meaning. Initiatives to bring changes and create righteous perceptions about them would never dare to stop. Five hundred years before the new era, the Greek philosopher Heraclitus said to his students; "Everything changes but the law of change". We live in a world which changes constantly. Fullan, one of the most outstanding representatives of the theory and practice of change writes; "This is a world in which change is a journey of unknown destination, where problems are our friends, where seeking assistance is a sign of strength, where simultaneous top down bottom up initiative merge where collegiality and individualism exist in productive tension..."

The giant span of internet would not be possible devoid of advanced technology. It is equivalent with the powerful growth of information which would not be made possible without an advanced technology, too. Information occupies unimaginable spaces and keeps growing every single minute. Without advanced technology even the availability of the slightest piece of information, be it the simplest one, would have been impossible.

\section{Comparing direct teaching with indirect teaching}

A genuine teaching method derived from the aims of the subject to be taught. One of its main qualities is the coherence it creates between the subject objectives and teaching activities. However, present-day development require teaching to be focused more on providing concepts, models, and abstractions, using strategies which concentrate more into problem investigation and (solution. Both types of learning should be combined in teaching processes with various strategies to make students capable of resolving problems, to think critically and work together. The reason is simple; the technologically developed societies require people who are able not only to memorize facts, which is done quite well by computers, but who can understand the information they need easily, are able to apply it effectively and make use of it all their lives. That is why it is necessary for teachers, firstly, to be capable of knowing and comparing models and to build their teaching and learning processes themselves, basing on basic knowledge and wants related to them. Learning results are classified in two big categories;

\section{Facts, rules and applying actions. Direct teaching}

\section{Concepts, models and abstractions. Indirect teaching}

In most cases, the first category implies a low level and simple conducts in the fields of knowledge as well as the emotional and psycho-motor ones. These include levels of knowing, understanding and applying the respective field cognition, levels of awareness, reactions and evaluation of the emotional fields, levels of imitation, manipulation and the accurateness of the psychomotor fields.

The second category displays higher and more complicated levels of conducts in the respective fields of knowledge. They include objectives in the levels of analysis, synthesis and the evaluation of the respective cognitive field; levels of organization and featuring in the emotional fields as well as levels of articulation and naturalization in the psychomotor fields.

In direct teaching the objective is fast acquisition of facts, rules and forming respective wants to them. The content of the subject is divided in small steps which are assimilated easily by means of explanation, examples and practical exercises, etc. Practice, both the led and the independent one, still under the full supervision of the teacher, helps students to actively be involved in the learning processes and to a highest degree.

The objective in indirect teaching is to involve students both in investigation and deliberation, which helps to forming and developing concepts in the form of models and abstractions. Teachers constantly use questions to lead students to discover and generalize as well as to be capable of evaluating their responses. In cases it is noticed that concepts are still unconsolidated, discussions in groups are used; this replaces the teacher's leading role and allows students to express themselves in various ways so consolidating concepts.

Therefore, in many cases, both models can be combined in the same lesson, since a small number of facts, rules or applying actions should be firstly assimilated before commencing with the acquisition of a concept, model or abstraction. In these terms, none of the models can be used to exclude the other; especially when the structure of critical thinking is made in compliance to the following condition;

Realization of efficient strategies, (forms, methods, techniques), makes possible for the application of many alternatives in the learning processes so helping students to develop managing and organizing and communication skills; it enhances 
diversity in students' learning and creativity. Realization of efficient strategies gives sense to the managing role (manager) of the teachers in the learning process and creates sound bases for the life-long learning. The term 'quality' in education is closely linked with contemporary models or various methods and techniques teachers use in the teaching processes while being committed to achieve educational objectives.

Teaching and effective learning require the use of appropriate pedagogic and methodological methods. Time has changed for traditional teaching "using a piece of chalk". Though we can't deny the attributes and advantages of this method in particular situations, but we should emphasize the great importance it has for every teacher, encouraging being a participant. While Kolbi sets the pupil in the center of learning, by evaluating his participation in the learning process as very important in creating his experience in learning. Silcock and Brundert established pupil centered teaching as an approach where the teacher is a facilitator and guidance of the learning process towards teaching where the teacher has control of everything in order to achieve the lesson aims. One of the most common class activities which in fact is the fundament of all learning and educational activities is the communication among teachers and pupils. It is fulfilled in many ways throughout the whole of the lesson time and it directly or indirectly implies all the pupils. It aims to improve the teaching quality. The techniques of asking questions which are included in the interactive teaching context are the recommended modules. Teachers should be open to the pupils' involvement in all stages of the lesson process. The teacher leads and organizes, whereas the pupil is involved everywhere. The teacher should intertwine learning with topics and projects which assure a massive pupils' participation. Pupils should be given the chance to get involved in working with pedagogical means of school texts. This task concentrates them in thinking and studying and the teacher makes them active to improve the scientific level in their subject. Also, the teachers should consider stimulating the feeling of self - confidence to the pupils, which is something to be appreciated.

\section{Working methodology}

The scientific question which arises for this work is: Do modern methods have priority compared to the traditional ones for an effective teaching? There have been a lot of studies for this topic, by specialists of the Albanian and foreign education. Literature is mainly based on studies conducted by Albanian experts or institutions, in publicity articles, or national reports and documents, or those by the international organizations in support of education. We think that by means of this work, we will contribute, though a little, in the existing literature because we will treat this topic not only by a theoretical point of view, but even by what really happens in our schools.

The hypothesis that we pose in this work is: The new teaching methods aren't still widely used because of the thought that authoritarian teacher- centered teaching is appreciated not just because of the past teaching models which are rooted in our sub conscience, but even because of the lack of material bases in our schools. Teachers sometimes hesitate to use new methods, though all educational instances offer continuous trainings about the contemporary methodology.

When we analyze a particular issue or phenomena, our aim is to establish the causative relation between them. This relation is expressed through variables. In Education, especially in teaching and the phenomena being studied, we distinguish a whole of variables, so a conditioned variable corresponds to a number of unconditioned variables.

In this work we distinguish these variables: Conditioned variables: Traditional and modern teaching method. Unconditioned variable: The selection of methodology by the teacher.

The population of this study are the teachers and the pupils of elementary school (Third, fourth, fifth classes) in Elbasan. The selected sample was chosen by chance (teachers from different schools in town) where we include public and non public schools.

While making this study, we have collected data from six schools in Elbasan. The schools which were involved in the study and the data for the observation were carried out in the same schools: "Europa" school. "Sule Harri "school, "Qamil Guranjaku "school, "Seit Pepa "school, "Arianiti school and "Imelda Lambertini" school.

By means of this instrument, we identified the methods, the techniques of the means that the teachers use in the six observed schools, to stimulate pleasure, desire, will and above all, motivation to successfully accomplish tasks in achieving the satisfactory and awaited results. There was a variety of means which teachers used ( not in all cases), where learning games had little part. 


\section{Data Analyses}

By calculating the frequency of each question involved in the questionnaire, it comes out that about $48 \%$ of the teachers use the motivating teaching method. The authoritarian method is used by $30 \%$ and liberal and democratic methods are less used. To stimulate pupils 'active learning, about $60 \%$ of the surveyed respond that they use pupil - centered teaching. Teacher - centered teaching is used in about $30 \%$. Interactive methods and the methods where the pupil feels leader are the most liked ones. Actually, to stimulate autonomy and self decision, $40 \%$ of the teachers offer the pupils total freedom in choosing and acting, 35\% offer the pupils limited freedom and about $20 \%$ of the teachers decide themselves what choices the pupils should make.

By elaborating the data, it results that traditional teaching methods are widely used in the second phase of the lesson, by about $60 \%$ of teachers. In the graphics below we notice that sometimes the methods are chosen based on the class level.

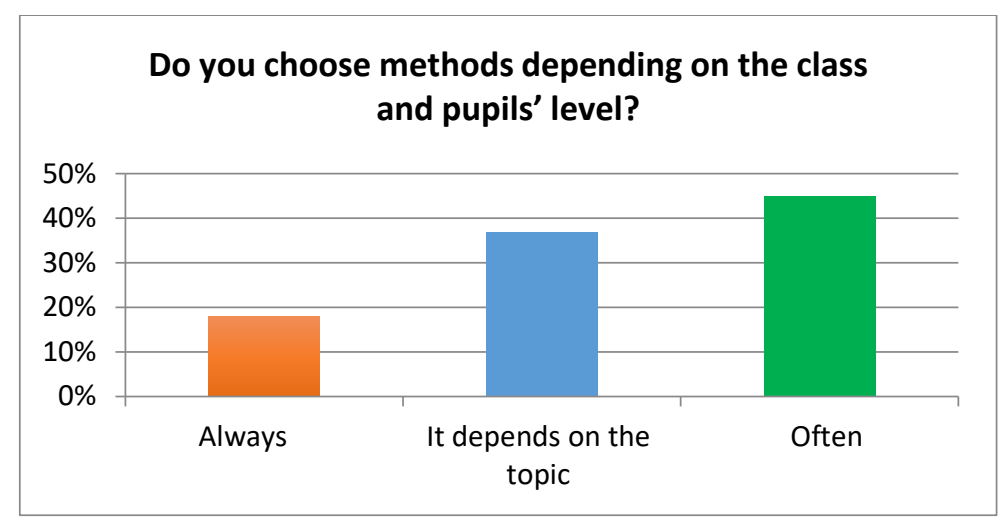

Most of the teachers think that using modern methods makes all pupils participate in the lesson. The other part thinks that these methods give pupils stable knowledge over time.

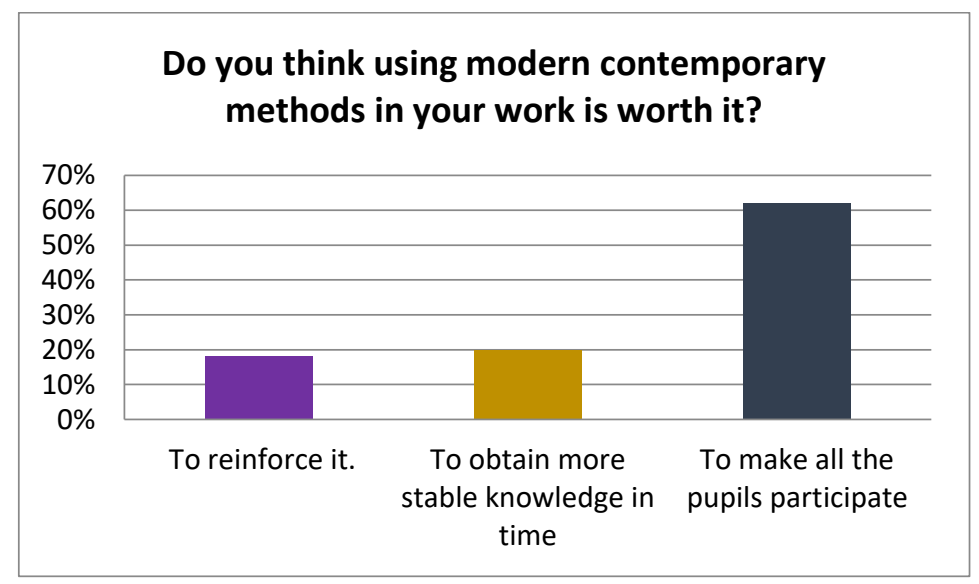

Nearly $40 \%$ of the teachers say that new techniques in the class make the pupil more active and practical. While $30 \%$ think that these techniques stimulate imagination, the other part think that these techniques distract pupils. $50 \%$ of the teachers plan the lesson with the new techniques because they consider them more effective and varied. The other part uses a mixture of these techniques and the traditional ones. 


\section{Conclusions and recommendations}

The reason for choosing this topic is three dimensional. Education is a very important topic which affects all citizens, and even more a nation and a country, because it establishes and strongly affects the development and progress of a society, country or nation. This becomes even more important actually when Albania is committed in the process of integrating into Europe and it aspires to join the EU club, and a well - educated and civilized society is more suitable for a European society. The third reason is professional interest, because we are teachers and the education issues and reforms in this sector affect our everyday work and professional interests.

While observing the lessons, the main focus was the use of methods and strategies to motivate pupils in class. Though our teachers try to implement new contemporary methods, they frequently use traditional methods in different phases of the lesson.

While observing we noticed that the pupils like the methods which stimulate collaboration spirit. They are more creative and free. Another element was noticed while observing in classes where the teacher used traditional methods and the pupils were more concentrated in the lesson and they completed in time all the assignments.

The model of old teachers which is set in our minds like the model teacher sometimes guides the teacher towards using traditional techniques.

Even in really effective classes regarding teaching and learning, the teachers use a very limited number of new techniques.

Along the questionnaires (we noticed that teachers usually prefer motivating pupil - centered teaching with interactive methods, but a major part of the surveyed (prefer (authoritarian teaching where the teacher guides and controls the class, mainly frontal discussion, ask - answer methods.

We noticed that in public "pilot" schools and the private ones where the class level was higher, the interactive methods were more easily applicable. In those classes where the level was lower, teachers felt insecure in selecting contemporary methods and preferred traditional teaching methods though in their lesson plan they had selected modern methods.

So we noticed some inconsistency between what the teacher had written in the lesson plan and what the teacher applied in the class.

Contemporary methods stimulate even a "sleepy" pupil and raise whole class participation in the learning process.

Another conclusion of this study was the tendency of teachers to have absolute control over the class because using contemporary methods created a certain enthusiasm and in this regard, sometimes teachers thought the time is too short to successfully complete all stages.

As teaching is an evolving process, it should walk alongside with social, cultural, political and technological development of society. At the end of this study we recommend what follows:

The teacher should gain more academic freedom, dissociating themselves from the past models because today's pupil is not yesterday's one. It has more opportunities to get information, knows technology well as has more freedom in behaving and thinking.

We think the teacher can use traditional and modern methods to make the lesson process more effective.

We also think that the teacher should dissociate himself /herself from authoritarian methods because this harms pupils' creativity, the teacher is seen with fear and not in the role he/she should have, the role of the inspirer.

Teachers should frequently be trained about contemporary methodology and these trainings should be attended with absolute seriousness to update their knowledge in the branch of didactics.

Exchanging experiences about selected methodologies, the most successful ones as well as the less successful ones, will enable teachers to compare and contrast ideas with colleagues and explore fearlessly the variety of modern methods. To require more specialized assistance from education experts and to require the improvement of those factors which obstacle their work for example: scarce material bases, a not on the proper standard text etc. 